\title{
EFEITO DA ADUBAÇÃO COM NITROGÊNIO, FÓSFORO E POTÁSSIO NO DESENVOLVIMENTO, NA PRODUÇÃO E NA QUALIDADE DE FRUTOS DO ABACAXI 'VITÓRIA'
}

\author{
LUIZ CARLOS SANTOS CAETANO², JOSÉ AIRES VENTURA², \\ ADELAIDE DE FÁTIMA SANTANA DA COSTA², ROGÉRIO CARVALHO GUARÇONI ${ }^{3}$
}

RESUMO- A cultivar de abacaxi 'Vitória' tem como principais características a resistência à fusariose, ausência de espinhos nas folhas, frutos de forma cilíndrica e de polpa branca. O objetivo deste trabalho foi avaliar o efeito de doses de $\mathrm{N}, \mathrm{P}_{2} \mathrm{O}_{5}$ e $\mathrm{K}_{2} \mathrm{O}$ no desenvolvimento da folha " $\mathrm{D}$ ", massa dos frutos, produtividade, produção de mudas e qualidade da polpa do fruto - sólidos solúveis (SS) e acidez titulável (AT). Os tratamentos foram constituídos de cinco níveis de $\mathrm{N}$ : $0 ; 214 ; 428 ; 642$ e $856 \mathrm{~kg} \mathrm{ha}^{-1}$; cinco níveis de $\mathrm{P}_{2} \mathrm{O}_{5}$ : 0; 75; $150 ; 225$ e $300 \mathrm{~kg} \mathrm{ha}^{-1}$, e cinco níveis de $\mathrm{K}_{2} \mathrm{O}: 0 ; 150 ; 300 ; 450$ e $600 \mathrm{~kg} \mathrm{ha}^{-1}$ dispostos em fatorial fracionado do tipo $(1 / 5) 5^{3} \mathrm{em}$ blocos. Doses crescentes de N promoveram maior crescimento da folha " $D$ ", produção de mudas, desenvolvimento do fruto e produtividade. A produtividade e a massa média do fruto com coroa alcançaram os valores máximos de $65,0 \mathrm{t} \mathrm{ha}^{-1} \operatorname{com} 647 \mathrm{~kg} \mathrm{ha}^{-1}$ de $\mathrm{N}$ e $1.247 \mathrm{~g}$ com $660 \mathrm{~kg} \mathrm{ha}^{-1} \mathrm{de} \mathrm{N}$, respectivamente. Os valores de AT e SS cresceram linearmente em função das doses de potássio implementadas, ao passo que a elevação das doses de nitrogênio apresentou efeito oposto. Mesmo com a baixa disponibilidade de P, não houve resposta a este nutriente.

Termos para indexação: Ananas comosus var. comosus, Fusarium guttiforme, fertilização, NPK.

\section{EFFECT OF FERTILIZATION WITH NITROGEN, PHOSPHORUS AND POTASSIUM ON GROWTH, YIELD AND FRUIT QUALITY OF PINEAPPLE 'VITORIA'}

\begin{abstract}
The pineapple cultivar Vitória has as main characteristics resistance to fusariosis, absence of spines on leaves, cylindrical fruit shape and white pulp. The objective of this study was to evaluate the effect of $\mathrm{N}, \mathrm{P}_{2} \mathrm{O}_{5}$ and $\mathrm{K}_{2} \mathrm{O}$ levels on " $\mathrm{D}$ " leaves development, fruit weight, yield, slip production and quality of fruit - soluble solids (SS) and titratable acidity (TA). The treatments consisted of five levels of $\mathrm{N}(0,214$, 428, 642 and $\left.856 \mathrm{~kg} \mathrm{ha}^{-1}\right)$, five levels of $\mathrm{P}_{2} \mathrm{O}_{5}\left(0,75,150,225\right.$ and $\left.300 \mathrm{~kg} \mathrm{ha}^{-1}\right)$, and five levels of $\mathrm{K}_{2} \mathrm{O}(0$, $150,300,450$ and $\left.600 \mathrm{~kg} \mathrm{ha}^{-1}\right)$, arranged in fractional factorial design (1/5) $5^{3}$ in blocks. Increasing doses of N promoted greater vegetative growth of " $\mathrm{D}$ " leaves, slip production, fruit development and yield. Yield and fruit weight with crown reached maximum values of $65.0 \mathrm{t} \mathrm{ha}^{-1}$ with $647 \mathrm{~kg} \mathrm{ha}^{-1}$ of $\mathrm{N}$ and 1,247 $\mathrm{g}$ with $660 \mathrm{~kg} \mathrm{ha}^{-1}$ of N, respectively. The values of TA (\%) and SS increased linearly with the levels of potassium applied, while increasing the levels of nitrogen had the opposite effect. Even with the low availability of P there was no response to this nutrient.
\end{abstract}

Index terms: Ananas comosus var. comosus, Fusarium guttiforme, fertilization, NPK.

\footnotetext{
${ }^{1}$ (Trabalho 088-13). Recebido em: 01-03-2013. Aceito para publicação em: 12-08-2013. Trabalho realizado com recursos do CNPq. 2Engenheiro Agrônomo, D.Sc., Pesquisador(a) do Incaper. E-mails: luizcaetano@incaper.es.gov.br; ventura@incaper.es.gov.br; adelaide@incaper.es.gov.br

${ }^{3}$ Engenheiro Agrícola, D.Sc., Pesquisador do Incaper. E-mail: guarconi@gmail.com
} 


\section{INTRODUÇÃO}

De acordo com Ventura et al. (2009), a fusariose (Fusarium guttiforme) é a doença mais severa na cultura do abacaxi no Brasil, com perdas estimadas em 30 a $40 \%$ dos frutos e de até $20 \%$ das mudas, e as cvs. tradicionalmente plantadas, Pérola e Smooth Cayenne, são suscetíveis à doença.

Lançada no ano de 2006, a cv. Vitória tem como características principais a resistência à fusariose, ausência de espinhos nas folhas e na coroa do fruto, frutos de forma cilíndrica e de polpa branca (VENTURA et al., 2009).

Para o desenvolvimento de todo o potencial produtivo de um novo genótipo, como é o caso da cv. Vitória, entre outras práticas, é fundamental adequada disponibilização de nutrientes pela adubação química e/ou orgânica. A indicação do manual de recomendação de calagem e adubação para o Estado do Espírito Santo (PREZOTTI et al., 2007), para a adubação do abacaxizeiro, independentemente da cultivar, é de $90 \mathrm{~kg} \mathrm{ha}^{-1}$ de $\mathrm{P}_{2} \mathrm{O}_{5}$ no plantio e mais 40 a $60 \mathrm{~kg} \mathrm{ha}^{-1}$ desse nutriente no primeiro ou no segundo mês após o plantio. Para o nitrogênio, a recomendação é de $320 \mathrm{~kg} \mathrm{ha}^{-1} \mathrm{e}$, para potássio $\left(\mathrm{K}_{2} \mathrm{O}\right)$, pode chegar a $480 \mathrm{~kg} \mathrm{ha}^{-1}$, dependendo do teor apresentado na análise de solo.

O nitrogênio é o nutriente que apresenta maior efeito sobre a produtividade do abacaxizeiro. Trabalhos realizados com diferentes cultivares, em vários locais do Brasil (TEISSON et al., 1979; BEZERRA et al., 1981; SPIRONELLO et al., 2004; GUARÇONI, M.; VENTURA, 2011; MARQUES et al., 2011), apontam efeito positivo do nitrogênio no aumento do peso dos frutos do abacaxi. Para a cv. Vitória, Silva et al. (2012) obtiveram aumento de peso de frutos e produtividade em resposta à adubação nitrogenada.

O abacaxi, no Estado do Espírito Santo, é cultivado principalmente em solo de baixa disponibilidade de fósforo, havendo, portanto, expectativa de resposta à adubação com este nutriente. O potássio normalmente tem menor efeito na produtividade do abacaxizeiro que o nitrogênio, mas está altamente relacionado à qualidade de frutos (BEZERRA et al., 1981; SPIRONELLO et al., 2004; GUARÇONI; VENTURA, 2011). Resultados de pesquisa mostraram que, além da produtividade do abacaxizeiro, a acidez e os sólidos solúveis são positivamente influenciados por doses de potássio crescentes, muitas vezes superiores às normalmente indicadas na literatura (LACOEUILHE, 1978; SPIRONELLO et al., 2004). O objetivo deste trabalho foi avaliar o efeito de doses de nitrogênio, fósforo e potássio no desenvolvimento das plantas, massa dos frutos, produtividade, produção de mudas e nas características de qualidade dos frutos do abacaxizeiro 'Vitória'.

\section{MATERIAL E MÉTODOS}

O experimento foi conduzido de maio de 2006 a abril de 2008, na Fazenda Experimental do Incaper de Pacotuba (20,75 S, 41,29 W e 130 m), localizada no município de Cachoeiro de ItapemirimES. O clima da região é caracterizado como quente e úmido, precipitação média anual de $1.000 \mathrm{~mm}$, temperatura mínima do mês mais frio variando de 11,8 a $18{ }^{\circ} \mathrm{C}$ e temperatura máxima do mês mais quente variando de 30,7 a $34{ }^{\circ} \mathrm{C}$. A análise da amostra de solo da área experimental, retirada antes da implantação do experimento na profundidade de 0 a $20 \mathrm{~cm}$, mostrou os seguintes resultados: $\mathrm{pH}=5,2$; $\mathrm{MO}=1,97 \mathrm{dag} \mathrm{kg}^{-1} ; \mathrm{P}=8,81 \mathrm{mg} \mathrm{dm}{ }^{-3} ; \mathrm{K}=99,0 \mathrm{mg}$ $\mathrm{dm}^{-3} ; \mathrm{Ca}, \mathrm{Mg}$ e T em $\mathrm{cmol}_{\mathrm{c}} \mathrm{dm}^{-3}$ 2,88, 0,87 e 6,67, respectivamente; $\mathrm{V}=61,2 \%$, e micronutrientes $(\mathrm{mg}$ $\left.\mathrm{dm}^{-3}\right) \mathrm{Zn}=6,8 ; \mathrm{Fe}=22,3 ; \mathrm{Mn}=88,75 ; \mathrm{Cu}=2,57$, e $\mathrm{B}=0,28$. A saturação por bases para a cultura do abacaxizeiro deve ser de $\mathrm{V}=60 \%$ (PREZOTTI et al., 2007), portanto não foi necessário aplicação de calcário na área experimental.

Os tratamentos foram constituídos de cinco doses de nitrogênio $(\mathrm{N})$ : 0; 214; 428; 642 e $856 \mathrm{~kg}$ ha $^{-1} ;$ cinco doses de fósforo $\left(\mathrm{P}_{2} \mathrm{O}_{5}\right): 0 ; 75 ; 150 ; 225 \mathrm{e}$ $300 \mathrm{~kg} \mathrm{ha}^{-1}$, e cinco doses de potássio $\left(\mathrm{K}_{2} \mathrm{O}\right): 0 ; 150$; $300 ; 450$ e $600 \mathrm{~kg} \mathrm{ha}^{-1}$. O experimento foi conduzido no delineamento fatorial fracionado $(1 / 5) 5^{3}$ do tipo (I, III, IV) (II), onde os tratamentos foram dispostos em cinco blocos, sendo possível pela superposição de quatro quadrados latinos ortogonais, como proposto por Conagin e Jorge (1982). Os dados foram submetidos à análise de variância, e os modelos de regressão foram testados a $5 \%$ de probabilidade. A análise de correlação teve a significância testada a $5 \%$ de probabilidade, pelo teste $\mathrm{t}$.

As parcelas foram formadas por seis linhas, com doze plantas em fileiras duplas, no espaçamento $90 \times 40 \times 30 \mathrm{~cm}\left(51.280\right.$ plantas ha $\left.^{-1}\right)$, sendo avaliadas as oito plantas do centro, nas quatro fileiras centrais. As doses de fósforo (como superfosfato triplo) foram aplicadas no sulco de plantio, e as de nitrogênio (na forma de ureia) e potássio (na forma de cloreto de potássio), divididas igualmente em quatro e três aplicações, respectivamente: aos 30; 120; 180 e 240 dias após o plantio (DAP), sendo que, aos 180 DAP, foi aplicado somente o adubo nitrogenado. Os adubos de cobertura foram aplicados na forma sólida, nas axilas das folhas basais das plantas. 
Avaliaram-se as seguintes características: comprimento, massa fresca e massa seca da folha tipo "D"; massa do fruto com e sem coroa; produtividade; comprimento do fruto e diâmetro medido na sua porção mediana; brix (sólidos solúveis-SS); acidez titulável (AT); número de mudas produzidas e por tipo; percentagem de plantas com aderência de mudas tipo filhote aos frutos; comprimento do pedúnculo (utilizou-se uma régua graduada); e percentagem de plantas com ocorrência de tombamento de frutos.

Aos 340 dias após o plantio, foi realizada a indução floral com aplicação de etephon, na concentração de 500 ppm, mais ureia a 2\%. Quinze dias antes da indução floral, foram amostradas folhas do tipo "D" em dez plantas úteis de cada parcela, para a avaliação do comprimento e da massa (matéria fresca e seca). As folhas foram cortadas em pedaços com cerca de $5 \mathrm{~cm}$ de comprimento e posteriormente secas em estufa de ventilação forçada a $70{ }^{\circ} \mathrm{C}$ até obterem massa constante. Após a colheita, amostras de polpa retiradas na porção mediana dos frutos foram desintegradas para extração do suco com o uso de um mini-processador tipo "mixer". A seguir, foram realizadas as determinações de SS com o uso de um refratômetro de bancada e da AT por titulação de amostra do suco com $\mathrm{NaOH}$ a $0,1 \mathrm{~N}$, tendo como indicador a fenolftaleína a $1 \%$.

\section{RESULTADOS E DISCUSSÃO}

O comprimento e as massas fresca e seca da folha " $D$ " foram influenciados somente pelas doses de $\mathrm{N}$, respondendo linearmente às doses aplicadas (Figura 1). Os valores obtidos na dose de $856 \mathrm{~kg} \mathrm{ha}^{-1}$ foram de 91,9 cm, 45,6 g e 6,1 g para comprimento e massas fresca e seca da folha "D", respectivamente. Também na cv. Vitória, Silva et al. (2012), em avaliação na época da indução floral, obtiveram, na dose de $600 \mathrm{~kg} \mathrm{ha}^{-1}$ de $\mathrm{N}$, valores inferiores para o comprimento e a massa fresca da folha ' $\mathrm{D}$ ', $70,9 \mathrm{~cm}$ e 41,7 g, respectivamente. Esse menor desenvolvimento vegetativo foi considerado pelos autores a causa da redução verificada posteriormente na produção de frutos.

O bom desenvolvimento vegetativo da planta na fase de pré-florescimento influencia diretamente na produção com a obtenção de frutos maiores e com maior massa. A massa das matérias fresca e seca e o comprimento da folha " $\mathrm{D}$ ", determinados na época da indução floral, apresentaram correlação positiva com a massa, o comprimento e o diâmetro do fruto (Tabela 1). Resultados semelhantes foram observados por Guarçoni e Ventura (2011) com a cultivar Gold MD-2.
As variáveis comprimento e diâmetro de fruto foram influenciadas somente pelas doses de $\mathrm{N}$ (Figura 2) com respostas quadráticas, com o máximo de $15,3 \mathrm{~cm}$, com $723 \mathrm{~kg} \mathrm{ha}^{-1}$ de N para comprimento de fruto, e $12,7 \mathrm{~cm}$ com $689 \mathrm{~kg} \mathrm{ha}^{-1}$ de $\mathrm{N}$ para diâmetro de fruto. Estas variáveis apresentaram elevada correlação positiva com a massa dos frutos (Tabela 1), mostrando a estreita relação existente entre as características de desenvolvimento do fruto.

A produtividade de frutos (com coroa) e a massa média de frutos foram significativamente influenciadas apenas pelas doses de $\mathrm{N}$, com valores máximos de $65,0 \mathrm{t} \mathrm{ha}^{-1} \mathrm{com} 647 \mathrm{~kg} \mathrm{ha}^{-1} \mathrm{de} \mathrm{N}, 1.247$ g com $660 \mathrm{~kg} \mathrm{ha}^{-1}$ de N e $1.138 \mathrm{~g}$ com $719 \mathrm{~kg} \mathrm{ha}^{-1}$ de $\mathrm{N}$, respectivamente, para produtividade, e massa do fruto com e sem coroa (Figura 3 ).

Os resultados obtidos indicam que a necessidade em $\mathrm{N}$ para alcançar a maior massa de fruto e produtividade na cv. 'Vitória'é superior a 320 $\mathrm{kg} \mathrm{ha}^{-1}$ de $\mathrm{N}$, que corresponde ao recomendado por Prezotti et al. (2007) para as lavouras comerciais do Estado do Espírito Santo. Para o Estado de São Paulo, a recomendação para a produtividade de abacaxi superior a $50 \mathrm{t} \mathrm{ha}^{-1}$ é de $600 \mathrm{~kg} \mathrm{ha}^{-1}$ de nitrogênio (QUAGGIO et al., 1996). Coelho et al. (2007) encontraram a massa máxima de fruto sem coroa da cultivar Jupi (1.200 g) aplicando 98,77 g/planta do formulado 20-05-20, o que, para uma população de 51.280 plantas ha $^{-1}$, equivaleria à aplicação de cerca de $1.013 \mathrm{~kg} \mathrm{ha}^{-1}$ de N. Silva et al. (2012), aplicando doses de $\mathrm{N}$ variando de 0 a $600 \mathrm{~kg} \mathrm{ha}^{-1}$ obtiveram a massa máxima do fruto do abacaxi 'Vitória' de $1.000 \mathrm{~g}$ aplicando $409,0 \mathrm{~kg} \mathrm{ha}^{-1}$ de $\mathrm{N}$ e máxima produtividade de $37,8 \mathrm{t} \mathrm{ha}^{-1}$, com $439 \mathrm{~kg} \mathrm{ha}^{-1}$ de $\mathrm{N}$. Os autores atribuíram os valores baixos de massa de fruto e produtividade ao crescimento lento das mudas oriundas de micropropagação usadas. Provavelmente a menor demanda de $\mathrm{N}$ para maximização da produção deve-se ao menor crescimento das plantas e, por consequência, a produção de frutos de menor massa.

As doses de $\mathrm{P}$ estudadas não influenciaram na produção do abacaxizeiro 'Vitória' mesmo com baixo teor do nutriente no solo $\left(8,81 \mathrm{mg} \mathrm{dm}^{-3}\right)$. Spironello et al. (2004) estudaram o efeito de doses de NPK na produção e qualidade de frutos do abacaxizeiro 'Smooth Cayenne' em solo com baixa disponibilidade de fósforo $\left(7,5 \mathrm{mg} \mathrm{dm}^{-3}\right)$ e também não encontraram efeito das doses de P no crescimento das plantas e na produção. Guarçoni e Ventura, (2011) descrevem a pequena ou a ausência de resposta do abacaxizeiro 'Gold MD-2' à adubação fosfatada. A reduzida ou nula resposta de produção do abacaxi à aplicação de P ocorre, provavelmente, pela intensa 
associação de fungos microrrízicos com as raízes do abacaxizeiro, elevando por consequência a absorção do P naturalmente encontrado no solo (GUARÇONI; VENTURA, 2011).

As variáveis de produção de frutos não foram influenciadas significativamente pelas doses de $\mathrm{K}_{2} \mathrm{O}$. Provavelmente, o teor de $99,0 \mathrm{mg} \mathrm{dm}^{-3}$ de $\mathrm{K}$ do solo da área experimental foi suficiente para proporcionar o satisfatório desenvolvimento da planta e dos frutos. Spironello et al. (2004) observaram resposta positiva à adubação com $\mathrm{K}_{2} \mathrm{O}$ na cv. Smooth Cayenne com a aplicação de $563 \mathrm{~kg}$ de $\mathrm{K}_{2} \mathrm{O}$ $\mathrm{ha}^{-1}$ para alcançar a massa máxima de $2.750 \mathrm{~g}$ e de $394 \mathrm{~kg} \mathrm{ha}^{-1}$ para a produtividade de $72,0 \mathrm{t} \mathrm{ha}^{-1}$. Veloso et al. (2001) verificaram comportamento positivo à adubação com $\mathrm{K}_{2} \mathrm{O}$ na cv.Pérola, com $1.128 \mathrm{~kg} \mathrm{ha}^{-1}$ de $\mathrm{K}_{2} \mathrm{O}$ para produtividade máxima de 79,0 $\mathrm{t} \mathrm{ha}^{-1}$.

O teor de sólidos solúveis ( ${ }^{\circ}$ Brix) e a acidez titulável (AT) foram influenciados pelas doses de $\mathrm{N}$ e $\mathrm{K}_{2} \mathrm{O}$ (Figuras 4 e 5). Os valores de AT e ${ }^{\circ}$ Brix cresceram linearmente em função das doses de $\mathrm{K}_{2} \mathrm{O}$ implementadas com valores máximos de $0,38 \%$ e 17,62 , respectivamente, ao passo que a elevação das doses de $\mathrm{N}$ apresentou efeito oposto, a despeito da resposta quadrática do ${ }^{\circ}$ Brix às doses de $\mathrm{N}$ aplicadas. Resultados semelhantes foram obtidos por Spironello et al. (2004) com 'Smooth Cayenne'. Por outro lado, Silva et al. (2012) não encontraram efeito do $\mathrm{N}$ sobre estas características no 'Vitória'. Bezerra et al. (1981) encontraram redução de ${ }^{\circ}$ Brix e aumento de translucidez da polpa de frutos da cv. Smooth Cayenne com doses crescentes de nitrogênio.

Efeito significativo dos tratamentos com $\mathrm{K}_{2} \mathrm{O}$ só foi observado sobre os valores de sólidos solúveis e da acidez titulável, mostrando a importância da adubação potássica nas características que conferem qualidade aos frutos de abacaxi. O efeito da adubação com $\mathrm{K}_{2} \mathrm{O}$ na elevação de Brix e da AT dos frutos do abacaxizeiro pode continuar com doses do nutriente superiores àquelas em que se alcança o máximo peso de frutos (LACOUEUILHE, 1978). Segundo Ventura et al. (2009), os teores mais elevados de AT e ${ }^{\circ}$ Brix proporcionam sabor mais apreciado aos frutos do abacaxizeiro 'Vitória'.

Somente as doses de $\mathrm{N}$ influenciaram significativamente no número de mudas produzidas. Tanto o número de mudas tipo filhote quanto o número total de mudas (filhotes+rebentões+filhotes rebentões) cresceram linearmente com o aumento das doses de $\mathrm{N}$ (Figura 6). O número de mudas tipo filhote aumentou $44,4 \%$, e o número total de mudas, $30 \%$ com a aplicação de $856 \mathrm{~kg} \mathrm{ha}^{-1}$ de N. Reinhardt e Cunha (1999) também obtiveram aumento de 31 a $46 \%$ no número de mudas tipo filhote produzidas quando dobraram a adubação NPK, normalmente usada para a cv. Smooth Cayenne. Estes resultados mostram a importância da adubação nitrogenada não só para as características de fruto como também sua influência para a produção de mudas, o que é importante para os produtores na obtenção de material propagativo para a formação de novas lavouras, bem como na rentabilidade da cultura, já que a comercialização de mudas pode significar mais uma fonte de renda para o abacaxicultor.

Por outro lado, a elevação das doses de N aumentou a percentagem de plantas que apresentaram aderência das mudas tipo filhote à base do fruto (Figura 6), o que é característica indesejável, pois com a colheita do fruto estas mudas se soltam e, como são muito pequenas para o plantio no campo, são normalmente perdidas. Este aumento foi de 14\% com a dose de $856 \mathrm{~kg} \mathrm{ha}^{-1}$ de nitrogênio. Mesmo assim, a aplicação de $\mathrm{N}$ nesta dose apresentou saldo positivo, uma vez que elevou o número de mudas produzidas em $44,4 \%$, suplantando a perda de mudas pela aderência ao fruto.

Não houve efeito significativo dos tratamentos sobre as variáveis comprimento médio do pedúnculo e percentagem de plantas com ocorrência de tombamento de frutos, com valores médios de $12,0 \mathrm{~cm}$ e $8,0 \%$, respectivamente. Estas variáveis mantêm estreita relação, uma vez que a ocorrência de pedúnculo longo sujeita ao tombamento de frutos, o que é indesejável, pois aumenta o percentual de queima solar dos frutos. 


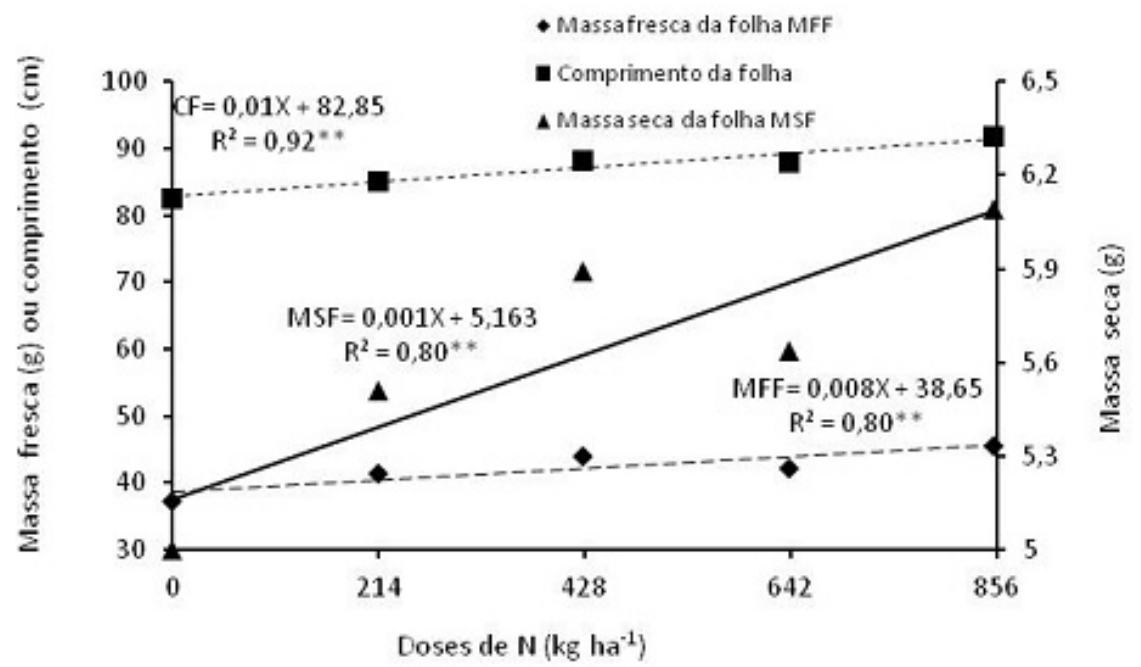

FIGURA 1- Massa fresca (g), massa seca (g) e comprimento (cm) da folha "D" em função das doses de nitrogênio aplicadas.

TABELA 1 - Resultado da análise de correlação linear entre variáveis de desenvolvimento da planta (folha "D") e do fruto.

\begin{tabular}{c|ccccc}
\hline & CF & MCC & MSC & CFD & MSFD \\
\cline { 2 - 6 } DF & $0,87^{* *}$ & $0,94^{* *}$ & $0,97^{* *}$ & $0,51^{* *}$ & $0,58^{*}$ \\
CF & - & $0,89^{* *}$ & $0,95^{* *}$ & $0,61^{*}$ & $0,64^{* *}$ \\
MCC & - & - & $0,97^{* *}$ & $0,58^{* *}$ & $0,63^{* *}$ \\
MSC & - & - & - & $0,61^{* *}$ & $0,66^{* *}$ \\
CFD & - & - & - & - & $0,89^{* *}$ \\
\hline
\end{tabular}

$\mathrm{DF}$ - Diâmetro do fruto; $\mathrm{CF}=$ Comprimento do fruto; $\mathrm{MCC}=$ Massa do fruto com coroa; $\mathrm{MSC}=$ Massa do fruto sem coroa; $\mathrm{CFD}=$ Comprimento da folha "D"; MSFD= Massa seca da folha "D"; * e ** significativo a $5 \%$ e $1 \%$ de probabilidade, pelo teste $t$, respectivamente.

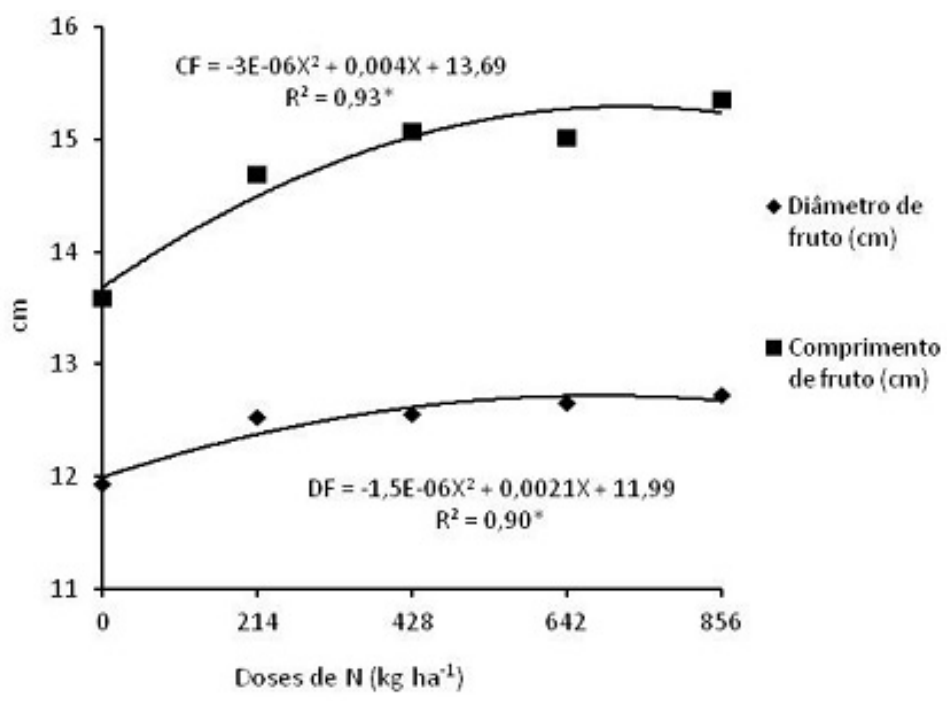

FIGURA 2- Comprimento e diâmetro de frutos do abacaxi 'Vitória' em função das doses de nitrogênio aplicadas. 


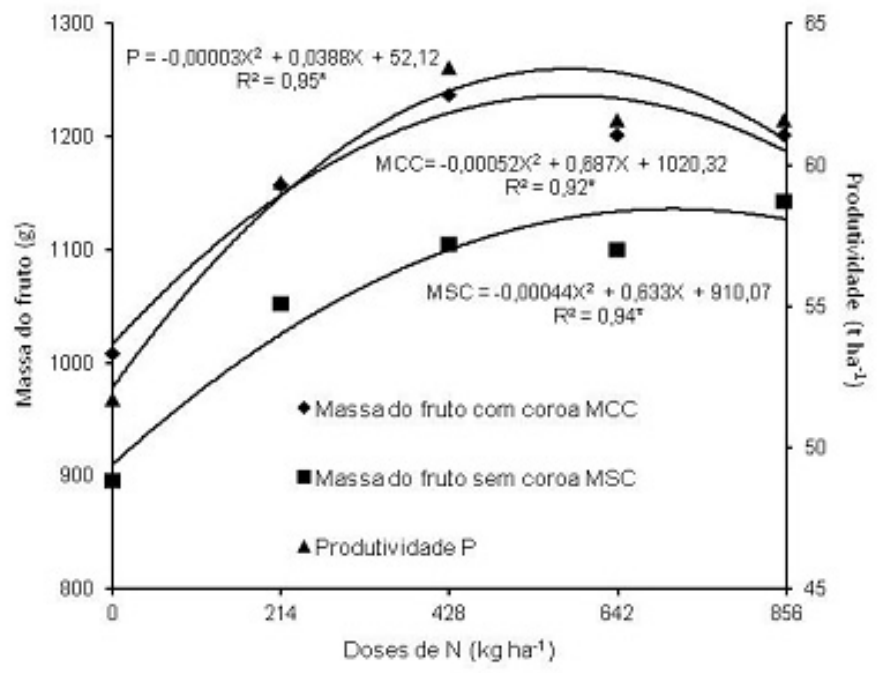

FIGURA 3- Produtividade de frutos com coroa e massa média de frutos do abacaxi 'Vitória' em função das doses de nitrogênio aplicadas.

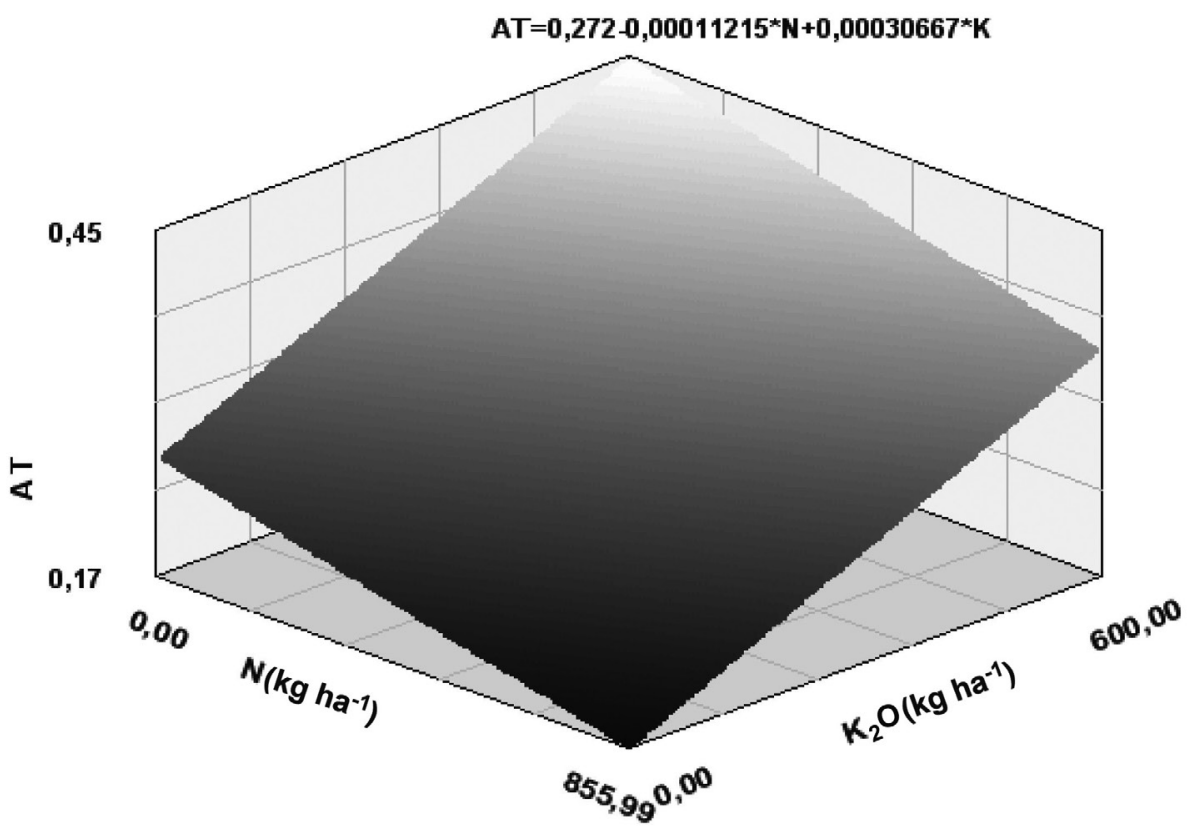

FIGURA 4- Acidez Titulável (AT\%) dos frutos do abacaxi 'Vitória' em função das doses de nitrogênio e potássio aplicadas. 


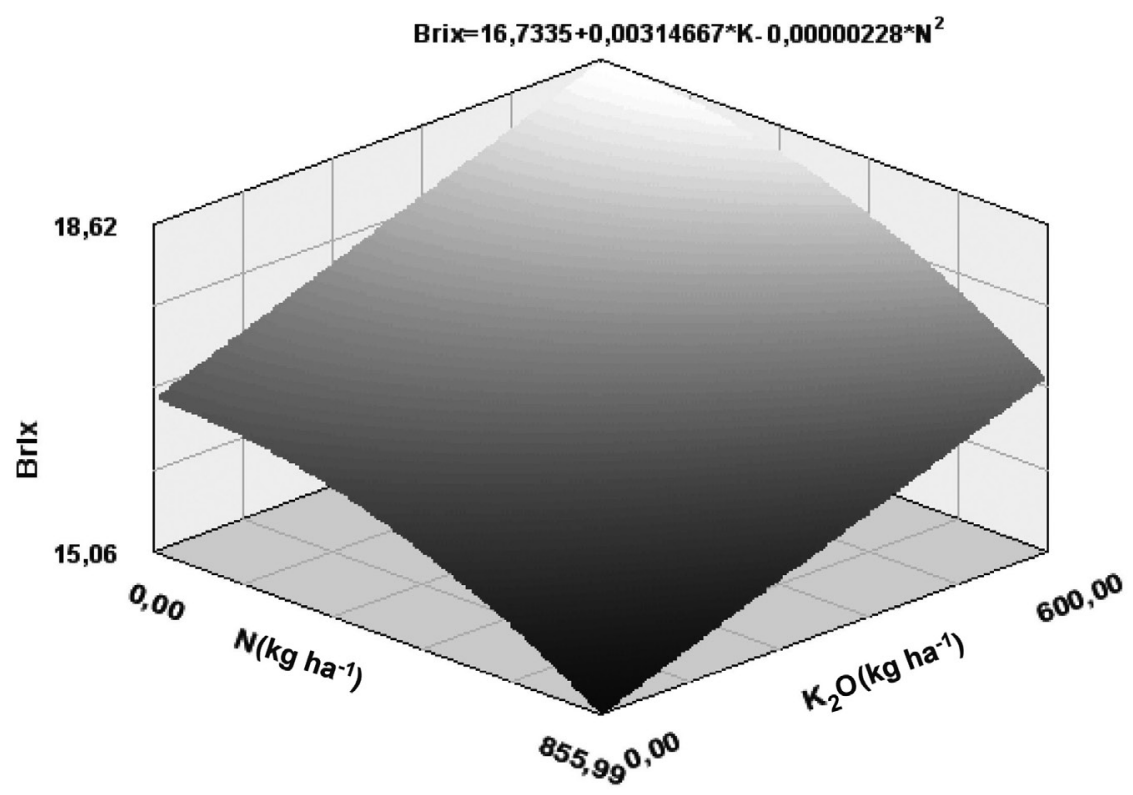

FIGURA 5 - Teor de sólidos solúveis ( ${ }^{\circ}$ Brix) dos frutos do abacaxi 'Vitória' em função das doses de nitrogênio e potássio aplicadas.

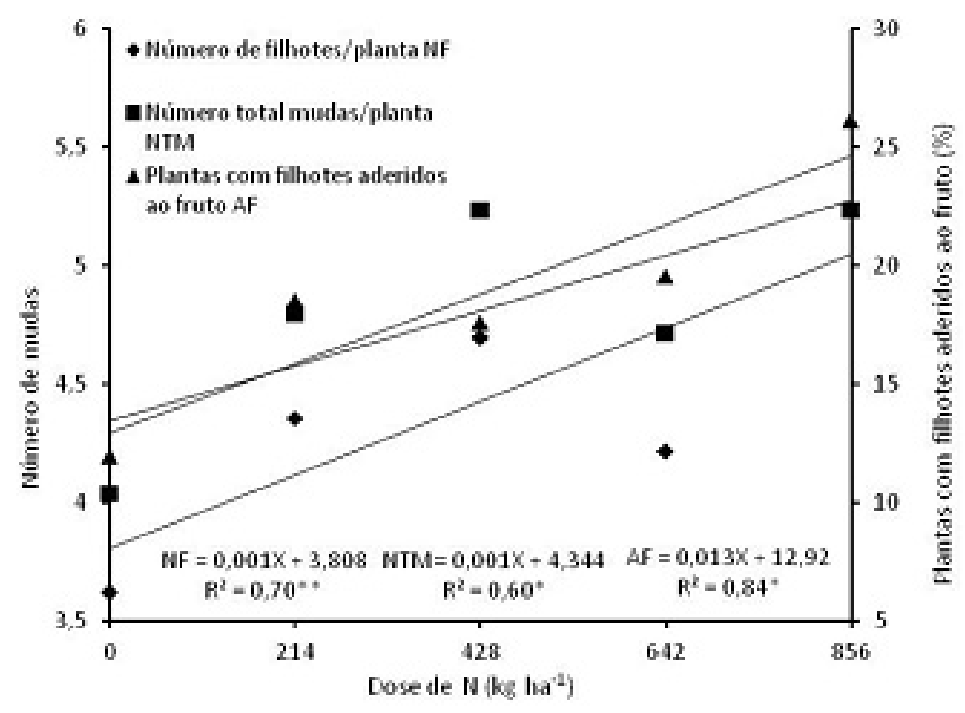

FIGURA 6 - Número de mudas por planta e porcentagem de plantas com filhotes aderidos ao fruto do abacaxi 'Vitória' em função das doses de nitrogênio aplicadas. 


\section{CONCLUSÕES}

1- A aplicação de doses crescentes de $\mathrm{N}$ promove maior comprimento e massa da folha " $\mathrm{D}$ ", maiores valores de diâmetro, comprimento, massa do fruto e produtividade do abacaxizeiro 'Vitória'. As características comprimento e massa da folha " $D$ ", bem como o comprimento e o diâmetro do fruto apresentam correlação positiva com a massa do fruto. Em contrapartida, não há resposta à aplicação de $\mathrm{P}$.

2- A máxima produtividade $\left(65,0 \mathrm{th} \mathrm{ha}^{-1}\right)$ é alcançada com a adição de $647 \mathrm{~kg}$ de $\mathrm{N} \mathrm{ha}^{-1}$.

3- O número de mudas tipo filhote aumenta $44,4 \%$, e o número total de mudas, $30 \%$ com a elevação das doses de $\mathrm{N}$ até $856 \mathrm{~kg} \mathrm{ha}^{-1}$.

4- Os valores de AT e ${ }^{\circ}$ Brix crescem linearmente em função das doses de $\mathrm{K}_{2} \mathrm{O}$ implementadas, ao passo que a elevação das doses de $\mathrm{N}$ apresenta efeito oposto.

\section{REFERÊNCIAS}

BEZERRA, J.E.F. MAAZE, U.C. SANTOS, V.F. LEDERMAN, I.E. Efeito da adubação nitrogenada, fosfatada e potássica na produção e qualidade do abacaxi cv. Smooth Cayenne. Revista Brasileira de Fruticultura, Jaboticabal, v.3, p. 1-5, 1981. Número único.

COELHO, R.I,; LOPES, J.C.; CARVALHO, A.J.C.; AMARAL; J.A.T.; MATTA, F.P. Estado nutricional e características de crescimento do abacaxizeiro 'Jupi' cultivado em latossolo amarelo distrófico em função da adubação com NPK. Ciência Agrotecnologia, Lavras, v. 31, n. 6, p. 1696-1701, 2007.

CONAGIN, A.; JORGE, J.P.N. Delineamento (1/5) (5 x 5 x 5) em blocos. Bragantia, Campinas, v. 41, n. 16 , p. $155-168,1982$

GUARÇONI M.A.; VENTURA, J.A. Adubação $\mathrm{N}-\mathrm{P}-\mathrm{K}$ e o desenvolvimento, produtividade e qualidade dos frutos do abacaxi 'Gold' (MD-2). Revista Brasileira de Ciência do Solo, Viçosa, MG, v.35, p.1367-1376, 2011.

LACOEUILHE, J.J. La fumure N-K de l'ananas em Cote d'Ivoire. Fruits, Paris, v. 33, n. 5, p. 341-348, 1978.
MARQUES, LS.; ANDREOTTI, M.; BUZETTI, S.; ISEPON, J.S. Produtividade e qualidade de abacaxizeiro cv. Smooth Cayenne, cultivado com aplicação de doses e parcelamentos do nitrogênio, em Guaraçaí-SP. Revista Brasileira de Fruticultura, Jaboticabal, v.33, n.3, p. 1004-1014, 2011.

PREZOTTI, L.C.; GOMES, J.A.; DADALTO, G.G.; OLIVEIRA, J.A. de. Manual de recomendação de calagem e adubação para o Estado do Espírito Santo - 5a aproximação. Vitória: SEEEA/INCAPER/ CEDAGRO, 2007. 305 p.

QUAGGIO, J.A.; RAIJ, B.V.; PIZA Jr, C.T. Frutíferas: abacaxi. In: RAIJ, B.V., CANTARELLA, H., QUAGGIO, J.A., FURLANI, A.M.C. Recomendações de adubação e calagem para o Estado de São Paulo. Campinas: Instituto Agronômico \& Fundação IAC, 1996. p.121-153. (Boletim Técnico, 100).

REINHARDT, D.H.; CUNHA, G.A.P. Métodos de propagação. In: CUNHA, G.A.; CABRAL, J.R.S.; SOUZA, L.F.S. O abacaxizeiro. Cultivo, agroindústria e economia. Brasília: Embrapa, 1999. p. 105-138.

SILVA, A.L.P.; SILVA, A.P.; SOUZA, A.P.; SANTOS, D.; SILVA S.M.; SILVA, V.B. Resposta do abacaxizeiro 'Vitória' a doses de nitrogênio em solos de tabuleiros costeiros da Paraíba. Revista Brasileira de Ciência do Solo, Viçosa, MG, v.36, p. 447-456, 2012.

SPIRONELLO, A.; QUAGGIO, J.A.; TEIXEIRA, L.A.J.; FURLANI, P.R.; SIGRIST, J.M.M. Pineapple yield and fruit quality effected by NPK fertilization in a tropical soil. Revista Brasileira de Fruticultura, Jaboticabal, v.26, n.1, p. 155-159, 2004

TEISSON, C.; LACOEUILHE, J.J.; COMBRES, J.C. Le brunissement interne de l'ananas. V. Recherches dês moyens de lute. Fruits, Paris, v. 34, n. 6, p. 399-415, 1979.

VELOSO, C.A.C.; OEIRAS, A.H.L.; CARVALHO, E.J.M.; SOUZA, F.R.S. Resposta do abacaxizeiro à adição de nitrogênio, potássio e calcário em latossolo amarelo do nordeste paraense. Revista Brasileira de Fruticultura, Jaboticabal, v. 23, n.2, p. 396-402, 2001.

VENTURA, J.A.; CABRAL, J.R.; MATOS, A.P.de; COSTA, H. 'Vitória': new pineapple cultivar resistant to fusariose. Acta Horticulturae, Leuven, v.822, p.51-56, 2009. 